\title{
Ambient GABA-Activated Tonic Inhibition Sharpens Auditory Coincidence Detection via a Depolarizing Shunting Mechanism
}

\author{
Zheng-Quan Tang, ${ }^{1}$ Emilie Hoang Dinh, ${ }^{1}$ Wei Shi, ${ }^{1,2}$ and Yong Lu ${ }^{1,2}$ \\ ${ }^{1}$ Department of Anatomy and Neurobiology, Northeastern Ohio Universities Colleges of Medicine and Pharmacy, Rootstown, Ohio 44272, and ${ }^{2}$ School of \\ Biomedical Sciences, Kent State University, Kent, Ohio 44240
}

\begin{abstract}
Tonic inhibition mediated by extrasynaptic $\mathrm{GABA}_{\mathrm{A}}$ receptors $\left(\mathrm{GABA}_{\mathrm{A}} \mathrm{Rs}\right)$ has emerged as a novel form of neural inhibition in the $\mathrm{CNS}$. However, little is known about its presence and function in the auditory system. Using whole-cell recordings in brain slices, we identified a tonic current mediated by $\mathrm{GABA}_{\mathrm{A}}$ Rs containing the $\delta$ subunit in middle/high-characteristic-frequency neurons of the chicken nucleus laminaris, the first interaural time difference encoder that computes information for sound localization. This tonic conductance was activated by ambient concentrations of GABA released from synaptic vesicles. Furthermore, pharmacological manipulations of the conductance demonstrated its essential role in coincidence detection. Remarkably, this depolarizing tonic conductance was strongly inhibitory primarily because of its shunting effect. These results demonstrate a novel role for tonic inhibition in central auditory information processing.
\end{abstract}

\section{Introduction}

Tonic inhibition refers to a persistently active conductance mediated by extrasynaptic $\mathrm{GABA}_{\mathrm{A}}$ receptors $\left(\mathrm{GABA}_{\mathrm{A}} \mathrm{Rs}\right)$ that are activated by low concentrations of ambient GABA (for review, see Farrant and Nusser, 2005; Belelli et al., 2009). In contrast to synaptic $\mathrm{GABA}_{\mathrm{A}}$ Rs that mediate the classical transient "phasic" IPSCs, extrasynaptic $\mathrm{GABA}_{\mathrm{A}}$ Rs have distinct physiological and pharmacological features, such as high GABA-binding affinity and low desensitization, as well as specific subunit combinations ( $\alpha 4 \delta$-, $\alpha 6 \delta$-, $\alpha 5 \gamma^{-}$, and $\varepsilon$-containing receptors). After being discovered $\sim 15$ years ago (Kaneda et al., 1995; Salin and Prince, 1996), tonic inhibition has been detected in multiple systems throughout the CNS and has been implicated in a variety of functions, including gain control (Chance et al., 2002; Mitchell and Silver, 2003), regulation of excitability (Brickley et al., 2001; Semyanov et al., 2003; Chadderton et al., 2004), learning and memory (Ruiz et al., 2010; Shen et al., 2010), modulation of behavioral states (Cope et al., 2005; Bright et al., 2007) and hippocampal gamma oscillation (Mann and Mody, 2010), and in the pathophysiology of postpartum depression (Maguire and Mody, 2008). However, little is known about the presence and function of tonic inhibition in the auditory system.

Localizing sound source using cues such as interaural time difference (ITD) is inherently important for the survival of ani-

Received Sept. 9, 2010; revised Feb. 5, 2011; accepted Feb. 18, 2011.

Author contributions: Z.-Q.T. and Y.L. designed research; Z.-Q.T., E.H.D., and W.S. performed research; Z.-Q.T., E.H.D., W.S., and Y.L. analyzed data; Z.-Q.T., E.H.D., and Y.L. wrote the paper.

This work was supported by National Institute on Deafness and Other Communication Disorders Grant R01 DC008984 (Y.L.). We thank Edwin Rubel, Laurence Trussell, Michael Burger, Joshua Gittelman, William Coleman, and Matthew Fischl for critical comments on a previous version of this manuscript. We thank Yanqiao Zhang and Huiyan Ma for technical assistance with Western blot. We also thank the two anonymous reviewers and the review editor whose constructive criticism have greatly improved this manuscript.

Correspondence should be addressed to Yong Lu at the above address. E-mail: ylu@neoucom.edu.

DOI:10.1523/JNEUROSCI.4733-10.2011

Copyright $\odot 2011$ the authors $\quad 0270-6474 / 11 / 316121-11 \$ 15.00 / 0$ mals. Neurons of the avian nucleus laminaris (NL), an analog of the mammalian medial superior olive (MSO), act as coincidence detectors for converging binaural excitatory inputs. NL is highly specialized to encode the extremely small ITDs (microsecond range) produced by sounds as a function of degrees of azimuth and each characteristic frequency (CF) (Grothe, 2003; Burger and Rubel, 2007; Kandler et al., 2009; Seidl et al., 2010). The high acuity of auditory coincidence detection in birds relies on several specialized physiological properties, including acceleration of EPSPs by activation of low-voltage-activated $\mathrm{K}^{+}$channels $\left(I_{\text {LTK }}\right)$ (Reyes et al., 1994, 1996; Kuba et al., 2003), spatial segregation of binaural excitatory inputs on bipolar dendrites (Parks and Rubel, 1975; Agmon-Snir et al., 1998), short-term synaptic depression at glutamatergic synapses (Kuba et al., 2002; Cook et al., 2003), and the site of axonal spike initiation (Kuba et al., 2006). Here, we report a novel mechanism associated with the GABAergic inputs to the NL. We discovered a constitutively active GABAergic current mediated by $\mathrm{GABA}_{\mathrm{A}} \mathrm{Rs}$ containing the $\delta$ subunit $(\delta$ $\mathrm{GABA}_{\mathrm{A}} \mathrm{Rs}$ ) in middle/high- but not low-CF NL neurons in the chick. This tonic current depolarized the cellular membrane, sharpened EPSPs, reduced spiking probability, and significantly improved coincidence detection. Remarkably, this depolarizing tonic conductance was strongly inhibitory primarily because of its shunting effect. Our study shows, for the first time, that a tonic GABA inhibition sharpens the auditory coincidence detection via a unique depolarizing shunting mechanism, and may improve localization of sound sources in birds.

\section{Materials and Methods}

Slice preparation and in vitro whole-cell recordings. Brainstem slices (250-300 $\mu \mathrm{m}$ in thickness) were prepared from chick embryos [embryonic day 11 (E11), E13, and E17-E19] and early hatchings [postnatal day 0 (P0) to P1; both sexes], as described previously (Tang et al., 2009). The ice-cold artificial CSF (ACSF) used for dissecting and slicing the brain tissue contained the following (in mM): 250 glycerol, $3 \mathrm{KCl}, 1.2 \mathrm{KH}_{2} \mathrm{PO}_{4}, 20 \mathrm{NaHCO}_{3}, 3 \mathrm{HEPES}$, 
1.2 $\mathrm{CaCl}_{2}, 5 \mathrm{MgCl}_{2}$, and 10 dextrose, $\mathrm{pH} 7.4$, when gassed with $95 \% \mathrm{O}_{2}$ and $5 \% \mathrm{CO}_{2}$. The procedures have been approved by the Institutional Animal Care and Use Committee at Northeastern Ohio Universities Colleges of Medicine and Pharmacy, and are in accordance with National Institutes of Health policies on animal use. Slices were incubated at $34-36^{\circ} \mathrm{C}$ for $>1 \mathrm{~h}$ in normal ACSF containing the following (in $\mathrm{mm}$ ): 130 $\mathrm{NaCl}, 26 \mathrm{NaHCO}_{3}, 3 \mathrm{KCl}, 3 \mathrm{CaCl}_{2}, 1 \mathrm{MgCl}_{2}, 1.25$ $\mathrm{NaH}_{2} \mathrm{PO}_{4}$, and 10 dextrose, $\mathrm{pH}$ 7.4. For recording, slices were transferred to a $0.5 \mathrm{ml}$ chamber mounted on a Zeiss Axioskop 2 FS Plus microscope (Zeiss) with a $40 \times$ water-immersion objective and infrared, differential interference contrast optics. The chamber was continuously superfused with ACSF (1-2 $\mathrm{ml} / \mathrm{min})$ by gravity. Recordings were performed at $34-36^{\circ} \mathrm{C}$.

Patch pipettes were drawn on an Electrode Puller PP-830 (Narishige) to $1-2 \mu \mathrm{m}$ tip diameter using borosilicate glass micropipettes (inner diameter of $0.86 \mathrm{~mm}$; outer diameter of 1.60 $\mathrm{mm}$ ) (VWR Scientific). The electrodes had resistances between 3 and $7 \mathrm{M} \Omega$ when filled with a solution containing the following (in $\mathrm{mM}$ ): 105 K-gluconate, $35 \mathrm{KCl}, 5$ EGTA, 10 HEPES, 1 $\mathrm{MgCl}_{2}, 4$ ATP-Mg, and 0.3 GTP-Na, with $\mathrm{pH}$ of 7.2 (adjusted with $\mathrm{KOH}$ ) and osmolarity between 280 and $290 \mathrm{mOsm} / \mathrm{L}$. The $\mathrm{Cl}^{-}$concentration $(37 \mathrm{~mm})$ in the internal solution approximated the physiological $\mathrm{Cl}^{-}$concentration (Tang et al., 2009) in NL neurons. Placement of recording electrodes was controlled by a motorized micromanipulator MP-225 (Sutter Instrument). The liquid junction potential was $10 \mathrm{mV}$, and data were corrected accordingly. Voltage- and currentclamp experiments were performed with an AxoPatch 200B and an AxoClamp 2B amplifier, respectively (Molecular Devices). Voltage-clamp recordings were obtained at a holding potential of $-60 \mathrm{mV}$. Data were low-pass filtered at 3-10 $\mathrm{kHz}$ and digitized with a Data Acquisition Interface ITC-18 (InstruTECH) at $20 \mathrm{kHz}$. Recording protocols were written and run using the acquisition and analysis software AxoGraph X (AxoGraph Scientific).

Synaptic stimulation and recordings of synaptic responses. Extracellular stimulation was performed using concentric bipolar electrodes with a tip core diameter of $127 \mu \mathrm{m}$ (World Precision Instruments). The stimulating electrodes were placed using a Micromanipulator NMN-25 (Narishige). Square electric pulses of $200 \mu$ s duration were delivered through a Stimulator A320RC (World Precision Instruments). Optimal stimulation parameters were selected for each cell to give postsynaptic potentials of maximal amplitude. Evoked EPSPs were elicited by electrical stimulation delivered to either the ipsilateral nucleus magnocellularis (NM), or to the fibers originating from the contralateral $\mathrm{NM}$ and innervating the ventral neuropils of the NL neurons. In experiments designed to test coincidence detection, the two stimulating electrodes were placed such that they were independent and the response latencies recorded from the same neuron were similar (Lu, 2009). The time interval between the two stimuli $(\Delta t)$ was varied to simulate ITD coding process. $\Delta t$ was defined as 0 when the firing probability, defined as the total number of spikes divided by the total number of stimuli, was maximal.
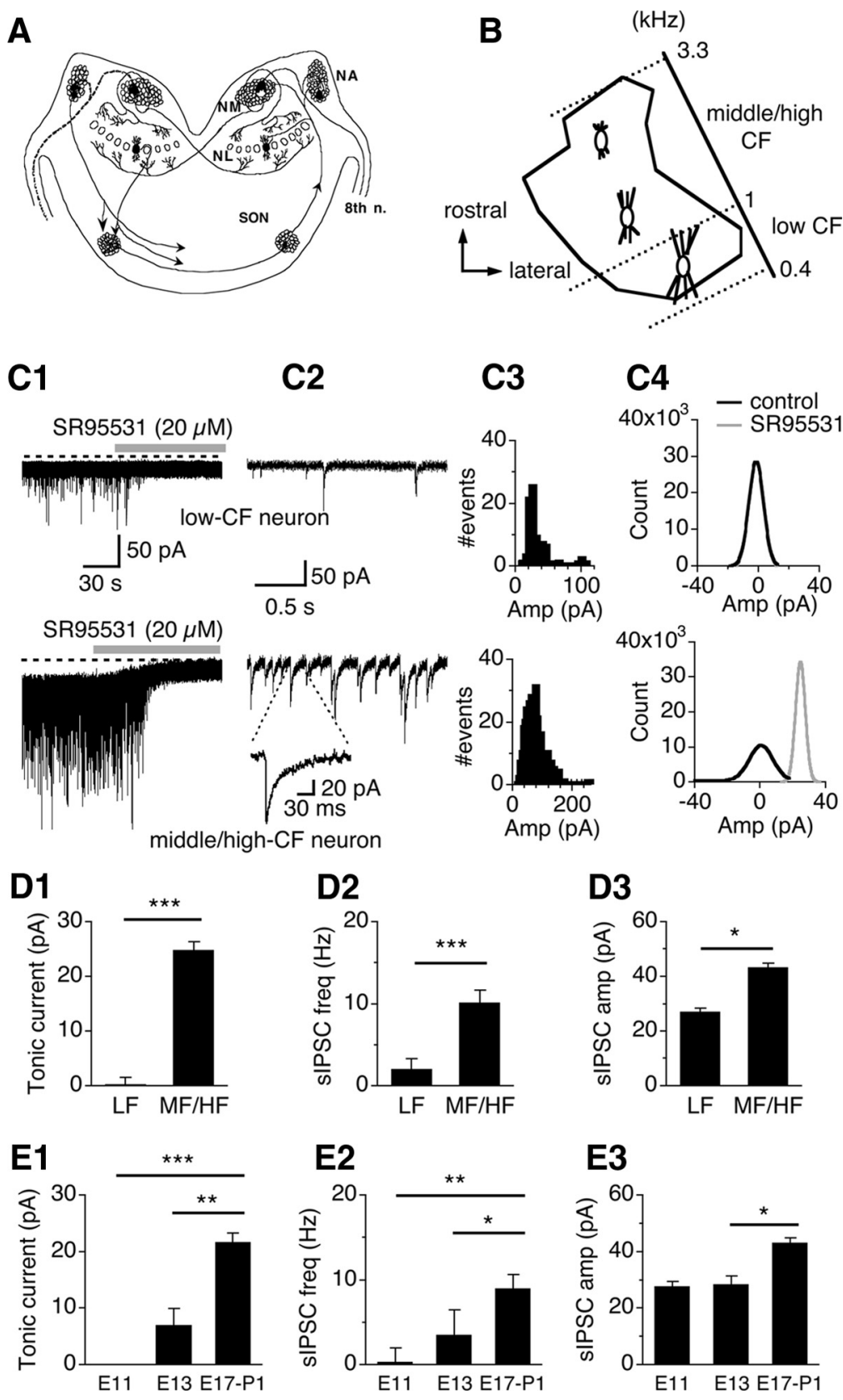

Figure 1. A tonic GABAergic current is present in middle/high- but not in low-CF NL neurons and is developmentally regulated. $\boldsymbol{A}, \boldsymbol{B}$, Schematic diagram of the avian auditory brainstem. NA, Nucleus angularis; NM, nucleus magnocellularis; SON, superior olivary nucleus; 8 th $\mathrm{n}$, cranial nerve VIII. The NL was divided into two regions according to the CF of the neurons (adapted from Rubel and Parks, 1975). C1, SR95531 (20 $\mu \mathrm{M})$, a specific GABA $\mathrm{A}_{\mathrm{R}}$ antagonist, blocked sIPSCs in both low- and middle/high-CF neurons, but only evoked an outward current in the middle/high-CF neuron. The dashed lines are artificial drawings to help visualize the effects of SR95531. C2, Recordings (2s) under control conditions at an enlarged scale, with one sIPSC being shown at higher temporal resolution. C3, Distribution of the amplitudes of the sIPSCs recorded from the two sampled neurons under control conditions. C4, All-point histograms of the baseline currents fitted with a Gaussian function (control, black; SR95531, gray). The amplitude of the tonic current was defined as the difference in the means of the Gaussian fit between control conditions and in presence of SR95531. D, Amplitude of the tonic current, frequency, and amplitude of the sIPSCs in middle/high-CF neurons (MF/HF, $n=71$ ) versus low-CF neurons $(n=10)$, from E17 to P1 animals. E, Development of the tonic current, the frequency, and amplitude ofs IPSCS[E11, $n=6 ; \mathrm{E} 13, n=9 ; \mathrm{E} 17-\mathrm{P} 1, n=81$; neurons sampled from all frequency regions were lumped (e.g., for E17-P1 animals, there were 71 middle/high-CF and 10 low-CF neurons)]. In this and subsequent figures, bars represent means \pm SEM. ${ }^{*} p<0.05,{ }^{* *} p<0.01$, and ${ }^{* * *} p<0.001, t$ test or ANOVA post hoc Fisher's test. Cells were held at $-60 \mathrm{mV}$ for voltage-clamp experiments. LF, MF, HF, Low-, middle-, and high-CF neurons of the NL, respectively.

All chemicals and drugs were obtained from Sigma-Aldrich except for 3-[[(3,4-dichlorophenyl)methyl] amino]propyl] diethoxymethyl)phosphinic acid (CGP52432), 11,12,13,13a-tetrahydro-7-methoxy-9-oxo-9Himidazo[1,5-a]pyrrolo[2,1-c] [1,4]benzodiazepine-1-carboxylic acid, ethyl ester (L-655,708), 6-imino-3-(4-methoxyphenyl)-1 $(6 H)$-pyridazine bu- 

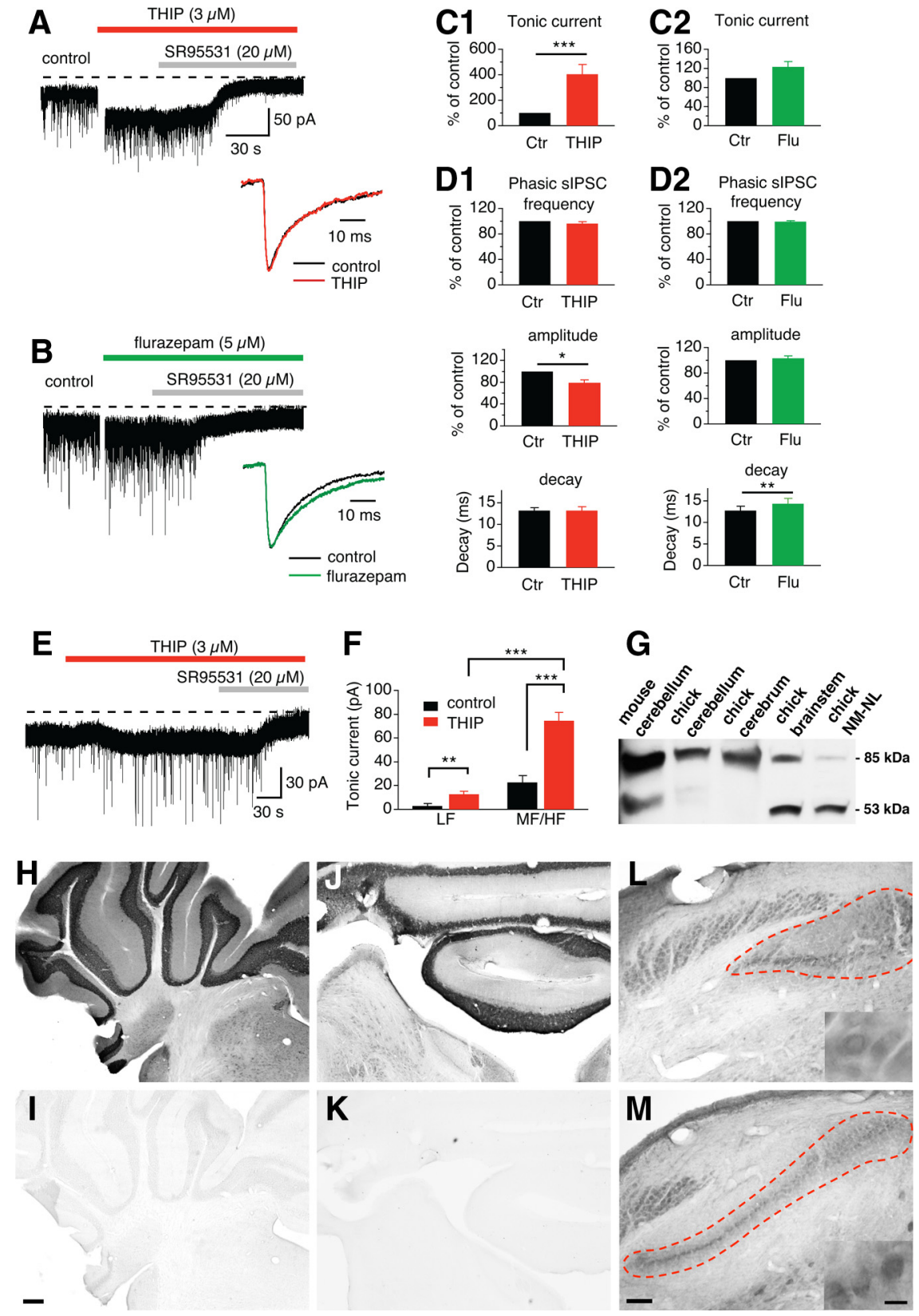

Figure 2. $\delta-G A B A_{A} R s$ mediate the tonic current. Pharmacological $(\boldsymbol{A}-\boldsymbol{F})$ and anatomical $(\boldsymbol{G}-\boldsymbol{M})$ evidence of $G A B A_{A} R \delta$ subunit expression. $\delta$-GABA $A_{A}$ Rs are known to be sensitive to the agonist THIP and insensitive to flurazepam. $A$, THIP ( $\left.3 \mu \mathrm{m}\right)$ enhanced the tonic current without altering the kinetics of sIPSCs in a middle/high-CF neuron. $\boldsymbol{B}$, In contrast, flurazepam (5 $\mu \mathrm{M})$ slowed the decay of SIPSCs without affecting the tonic current. C, THIP $(3 \mu \mathrm{m} ; n=6)$ but not flurazepam $(5 \mu \mathrm{m} ; n=5)$ enhanced the tonic current. $D$, Effects of THIP and flurazepam on phasic sIPSCS. E, F, THIP $(3 \mu \mathrm{m})$ revealed a small tonic current in low-CF neurons $(n=8)$. Note that THIP at the same concentration dramatically enhanced the tonic current in middle/high-CF neurons $(n=6)$, resulting in a tonic current of absolute amplitude approximately sixfold higher than that for low-CF neurons. $G$, Western blot confirmed the specificity of the antibody against the $\delta$ subunit. $\boldsymbol{H}-\boldsymbol{K}$, The $\delta$ subunit was strongly expressed in the cerebellum of the mouse $(\boldsymbol{H})$ and the chick $(J)$, and the staining was negative when the primary antibody was omitted $(\boldsymbol{I}, \boldsymbol{K}) . \boldsymbol{L}, \boldsymbol{M}$, The $\delta$ subunit was expressed in the chicken NL, without an obvious graded distribution along the tonotopic axis. The dashed lines define the boundaries of the $\mathrm{NL}$ (in $L$, low-CF region; in $M$, middle/high-CF region). Note multiple layers of cell bodies at the very lateral NL. The insets show a few cells at a higher magnification. Scale bars: (in $\boldsymbol{I}) \boldsymbol{H}-\boldsymbol{K}, 200 \mu \mathrm{m}$; (in $\boldsymbol{M}$ ) $\boldsymbol{L}, \boldsymbol{M}, 100 \mu \mathrm{m}$; inset, $15 \mu \mathrm{m}$.

tanoic acid (SR95531), and 4,5,6,7-tetrahydroisoxazolo[5,4-c]pyridin-3-ol (THIP), which were obtained from Tocris. Drugs were bath-applied using a gravity-driven perfusion system, except for concanamycin A, the stock solution of which was prepared in DMSO, and the final solution was prepared in a small volume $(\sim 2 \mathrm{ml})$ of ACSF in which slices were preincubated for $>1.5$ $\mathrm{h}$ before electrophysiological recordings.

Data analysis. The measurement of the tonic current was determined by following a protocol published previously (Glykys et al., 2007). Briefly, chart recordings of the holding current under voltage-clamp mode were obtained at a holding potential of $-60 \mathrm{mV}$, in presence of glutamate receptor antagonists $(50 \mu \mathrm{M}$ DNQX and $100 \mu \mathrm{M}$ APV for AMPA and NMDA receptors, respectively). Once a stable baseline under the control conditions was obtained, the $\mathrm{GABA}_{\mathrm{A}} \mathrm{R}$ blocker (either $20 \mu \mathrm{M}$ SR95531 or $40 \mu \mathrm{M}$ bicuculline) was bath-applied. The tonic current, if any, could be qualitatively observed as a baseline shift of the holding current. To quantitatively analyze the amplitude of the tonic current, a 10-30 s period of the recordings under each condition was used for all-points histogram plots. To construct such plots in AxoGraph, an initial segment of the chart recordings that did not contain spontaneous IPSCs (sIPSCs) was set as the baseline (amplitude set to zero). The amplitudes of all the data points in the recording under the control condition were transferred to a histogram plot, and the amplitudes of all the data points in the recording under a drug condition were transferred to another histogram plot. Because the sampling rate was $20 \mathrm{kHz}$, each plot contained $200,000-600,000$ points. A Gaussian fit was applied to the histogram plot. Under control and other conditions in which sIPSCs were present, the histogram had a skewed distribution toward synaptic events, and the Gaussian fit was applied only to the unskewed portion of the distribution. The mean of the fitted Gaussian was considered as the mean of the holding currents. Thus, the amplitude of the tonic current was defined as the difference in the means of the Gaussian fit between control conditions and in presence of SR95531 or bicuculline.

The resting membrane potential was read from the amplifiers immediately after the whole-cell configuration was established. The input resistance was calculated from the voltage responses to a somatic current injection $(-100 \mathrm{pA})$, which gave rise to a similar voltage change to the size of EPSPs. sIPSCs were detected by a template using a function for product of exponentials, $f(t)=[1-\exp (-t /$ rise time $)]^{*} \exp (-t /$ decay $\tau)$, in which $t$ stands for time and $\tau$ for time constant. The values of the parameters for the template were determined based on the average of real events. The detection threshold was three times the noise SD, which allowed the detection of most of the events with the least number of false positives.

Graphs were made in Igor (Wavemetrics). Means and SEMs are reported. Statistical differences were determined by paired or unpaired $t$ tests, unless otherwise indicated.

$G A B A_{A} R-\delta$ subunit immunostaining and Western blot analysis. For immunostaining of the $\delta$ subunit (GABRD), we followed the protocol by Peng et al. (2002) with slight modifications. E21 to P15 chicks were used. Embryos were rapidly decapitated and their brains were immediately immersed in $4 \%$ paraformaldehyde (PFA), $\mathrm{pH} 7.4$, in phosphate buffer, whereas hatched animals were deeply anesthetized (Fatal-Plus; Vortech Pharmaceuticals) and transcardially perfused with PFA. The brains were postfixed in PFA for $2 \mathrm{~h}$ at room temperature and then overnight at $4^{\circ} \mathrm{C}$, rinsed thoroughly in PBS, and vibratome-sliced (50 $\mu \mathrm{m}$ in thickness). Endogenous peroxidase activity was quenched for $30 \mathrm{~min}$ in $1 \% \mathrm{H}_{2} \mathrm{O}_{2}$ 
Table 1. Effects of drugs on tonic and phasic GABAergic currents in the middle/high-CF neurons

\begin{tabular}{|c|c|c|c|c|c|c|}
\hline \multirow[b]{2}{*}{ Drugs $(n)$} & \multicolumn{2}{|c|}{ Tonic current (pA) } & \multicolumn{2}{|c|}{ sIPSC frequency (Hz) } & \multicolumn{2}{|c|}{ sIPSC amplitude (pA) } \\
\hline & Control & Drug & Control & Drug & Control & Drug \\
\hline THIP (6) & $22.7 \pm 5.8$ & $74.6 \pm 6.8^{* * *}$ & $10.1 \pm 2.6$ & $9.6 \pm 2.5$ & $41.7 \pm 4.4$ & $32.6 \pm 3.8^{*}$ \\
\hline Concanamycin A & $27.6 \pm 8.0(5)$ & $6.9 \pm 2.4(6)^{*}$ & $6.0 \pm 1.0(5)$ & $1.4 \pm 0.5(6)^{* *}$ & $55.2 \pm 5.3(5)$ & $38.8 \pm 4.4(6)^{*}$ \\
\hline L-655,708 (5) & $30.8 \pm 6.4$ & $33.1 \pm 7.5$ & $9.3 \pm 3.6$ & $9.4 \pm 3.3$ & $36.1 \pm 8.8$ & $35.8 \pm 9.4$ \\
\hline $0 \mathrm{~mm} \mathrm{Ca}^{2+}(5)$ & $19.8 \pm 1.9$ & $7.0 \pm 2.3^{* * *}$ & $7.8 \pm 1.8$ & $4.2 \pm 1.3^{*}$ & $41.4 \pm 9.2$ & $32.6 \pm 5.9$ \\
\hline Baclofen (5) & $26.7 \pm 1.3$ & $5.6 \pm 2.1^{* * *}$ & $10.1 \pm 0.4$ & $5.6 \pm 0.6^{* *}$ & $28.1 \pm 2.6$ & $29.9 \pm 3.5$ \\
\hline
\end{tabular}

$n$, Number of cells.

${ }^{*} p<0.05$, ${ }^{* *} p<0.01$, and ${ }^{* * *} p<0.001$, Student's paired $t$ test, except that for concanamycin A, unpaired $t$ test was used, and the number of cells is shown in parentheses after the data sets because the cells recorded under the control condition (slices pretreated in $0.5 \%$ DMSO) were different from the cells recorded under the drug condition.

and nonspecific binding sites were blocked for $2 \mathrm{~h}$ in $10 \%$ normal goat serum (in $0.3 \%$ Triton-X), with avidin $(200 \mu \mathrm{l} / \mathrm{ml})$, in Tris-buffered saline (TBS), $\mathrm{pH}$ 7.6. For antigen retrieval, sections were heated (70$\left.90^{\circ} \mathrm{C}\right)$ in sodium citrate buffer $(0.05 \mathrm{M})$ and $0.9 \% \mathrm{NaCl}$ solution. After rinse with TBS, sections were incubated overnight with an anti-GABRD antibody raised in rabbits (1:100; Millipore), with $2 \%$ goat serum and biotin $(200 \mu \mathrm{l} / \mathrm{ml})$, followed by incubation with the biotinylated goat anti-rabbit secondary antibody (1:1000 for $2 \mathrm{~h}$ ). The signal was amplified using an avidin-biotin-horseradish peroxidase-based system (Vector Laboratories). Sections were rinsed in TBS before nickel- or osmiumintensified diaminobenzidine exposition, mounted on slides, and allowed to air dry. Finally, slices were dehydrated, cleared in xylene, and coverslipped using Permount mounting media (Thermo Fisher Scientific). Negative control experiments were performed by omitting the primary antibody. Images were taken with a high-resolution CCD camera system (Spot camera; Diagnostic Instruments) mounted on an Olympus Provis AX70 microscope.

All reagents for Western blot analysis were purchased from Thermo Fisher Scientific unless otherwise stated. Eight chicks (P3) and two mice (P21) were deeply anesthetized by isoflurane inhalation (Aerrane; Baxter International) and rapidly decapitated. The brains were immediately dissected out in ice-cold ACSF. Tissues of interest were collected into vials filled with lysis buffer (in mm: 20 Tris- $\mathrm{HCl}, 10$ EDTA, 10 EGTA, $2 \mathrm{MgCl}_{2}$, 250 sucrose, $\mathrm{pH}$ 8.0). After homogenizing the tissues, total proteins were extracted by centrifugation and their concentration was determined by BCA assay. Proteins were loaded ( $50 \mu \mathrm{g} /$ lane), separated by $10 \%$ SDSPAGE, and wet-transferred onto PVDF (polyvinylidene difluoride) membranes $(100 \mathrm{~V}, 1 \mathrm{~h})$ which were blocked in 5\% skim milk-TBSTween, pH 7.5 ( $1 \mathrm{~h})$, before incubation with anti-GABRD antibody (1: 200 in blocking buffer) overnight at $4^{\circ} \mathrm{C}$. Membranes were then rinsed and incubated $1 \mathrm{~h}$ with horseradish peroxidase-conjugated goat antirabbit IgG (1:3000; Bio-Rad), processed for chemiluminescent reaction (5 min; ECL kit), and developed on film.

\section{Results}

\section{$\mathrm{A} \mathrm{GABA}_{\mathrm{A}} \mathrm{R}$-mediated tonic current is expressed in the} middle/high-CF NL neurons

NL neurons receive GABAergic inputs (Carr et al., 1989; Code et al., 1989), which are unusually depolarizing in the chick by the time of hatching (Tang et al., 2009), a time at which hearing has been established (Jackson and Rubel, 1978) and sound localization is fairly mature (Gray and Rubel, 1985). GABA ${ }_{A} R$-mediated tonic currents were investigated by recording whole-cell currents from NL neurons in presence of antagonists for ionotropic glutamate receptors. The recordings were performed under normal physiological recording conditions [i.e., without application of exogenous $\mathrm{GABA}$ and with an intracellular $\mathrm{Cl}^{-}$concentration $(37 \mathrm{~mm})$ approximating the physiological concentration that we measured with gramicidin-perforated patch recordings in a previous study (Tang et al., 2009)]. Because the chicken NL is tonotopically organized (Rubel and Parks, 1975), in this study the NL was approximately divided into two (low and middle/ high) CF regions (Fig. 1 A,B). Application of SR95531 (20 $\mu \mathrm{M})$, a competitive $\mathrm{GABA}_{\mathrm{A}} \mathrm{R}$ antagonist, completely abolished the sIPSCs in both the low- and middle/high-CF neurons. Interestingly, SR95531 also revealed an outward current, but only in the middle/high-CF group (Fig. 1C). The amplitude of the tonic current in middle/high-CF neurons was $24.8 \pm 1.6 \mathrm{pA}(n=71)$, and it was minimal in low-CF neurons $(0.2 \pm 1.2 \mathrm{pA} ; n=10)$ (Fig. $1 D 1)$. Bicuculline $(40 \mu \mathrm{M})$, another $\mathrm{GABA}_{\mathrm{A}} \mathrm{R}$ antagonist, produced similar effects as those of SR95531 (tonic current of $32.3 \pm$ $6.1 \mathrm{pA}$ in middle/high-CF neurons; $n=5$ ) (data not shown), further confirming the presence of tonic currents in middle/ high-CF neurons. However, for subsequent experiments we preferred to use SR95531, rather than bicuculline, because of the possible blockade of potassium channels by bicuculline (Debarbieux et al., 1998).

Because the frequency and amplitude of sIPSCs were significantly higher in middle/high-CF neurons than in low-CF neurons (Fig. $1 D 2, D 3$ ), it is possible that the tonic current in middle/ high-CF neurons resulted from temporal summation of sIPSCs. However, our results argue against this possibility. First, we noted that, during application of SR95531, the amplitude of the tonic current in middle/high-CF neurons continued to grow even after all sIPSCs were blocked. Second, we observed that, under control conditions, most individual sIPSC events were distinct, with only occasional presence of bursts (Fig. 1C2). These data suggest that the tonic current amplitude increases with the sIPSC frequency and amplitude, not because sIPSCs temporally summate but likely because the ambient GABA concentration parallels the synaptic activity. Pharmacological evidence supporting this conclusion is presented later.

To further explore the relationship between synaptically released GABA and the tonic current, we examined the development of the GABAergic transmission in younger embryos (E11 and E13). Synaptic $\mathrm{GABA}_{\mathrm{A}} \mathrm{R}$-mediated responses in NL neurons were first recorded at E11, and application of SR95531 did not reveal any tonic current at this age $(0.1 \pm 1.6 \mathrm{pA} ; n=6)$. At E13, the frequency of sIPSCs increased to a few hertz, and a tonic current was first detectable $(7.0 \pm 2.9 \mathrm{pA} ; n=9)$. The amplitude of the tonic current recorded from NL neurons obtained from late embryos (E17-E19; $n=75$ ) was not significantly different from that of early hatchlings ( $\mathrm{P} 0-\mathrm{P} 1 ; n=6)$, so data from these two age groups were combined. At E17 to P1, the amplitude of the tonic current significantly increased $(21.7 \pm 1.6 \mathrm{pA} ; n=81)$, as did the frequency and amplitude of sIPSCs (Fig. 1E). Therefore, the tonic current in NL neurons is developmentally regulated, and its amplitude appears to correlate with the strength of the synaptic inhibition. 
A
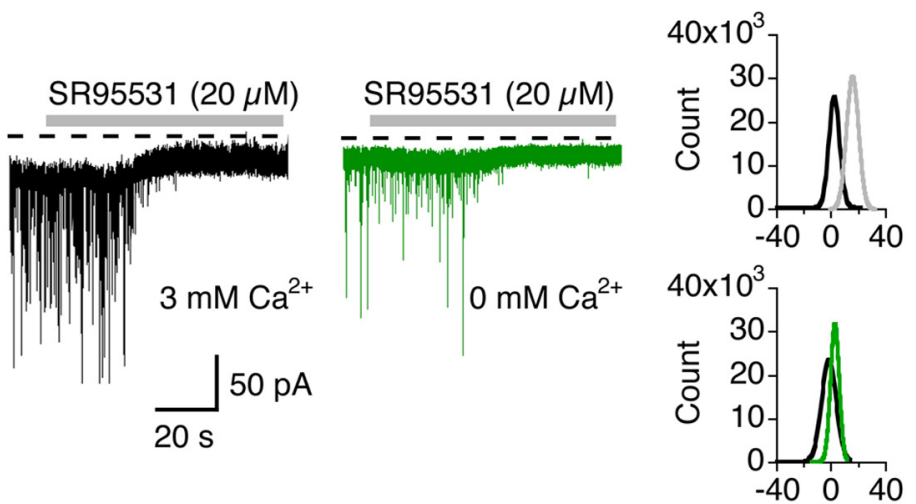

B

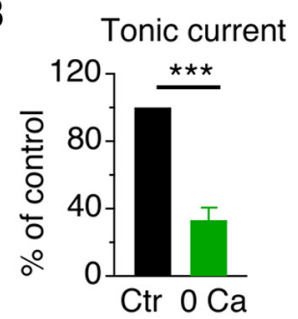

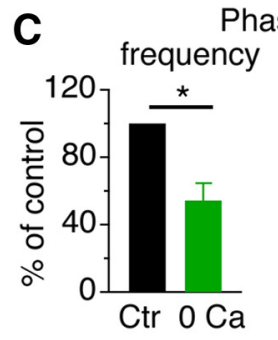

Phasic sIPSC

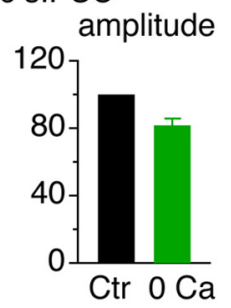

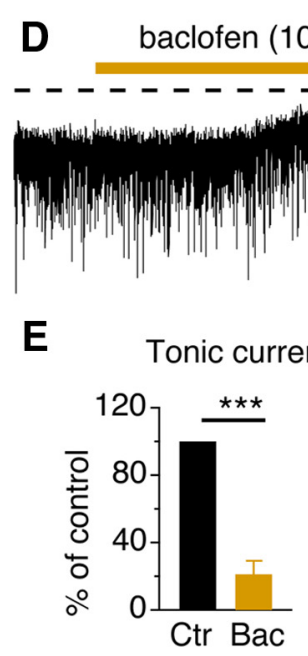

G

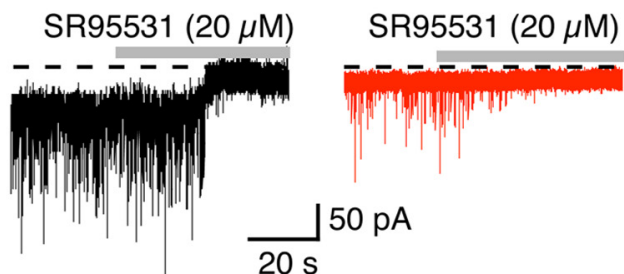

DMSO

$\mathbf{F}$

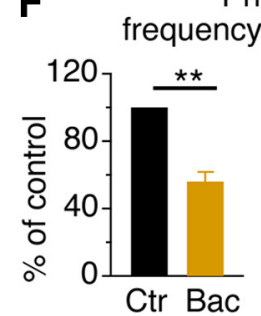

Phasic SIPSC

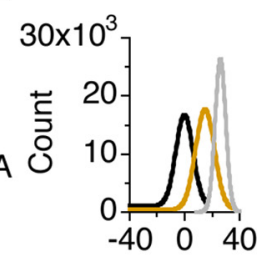

amplitude
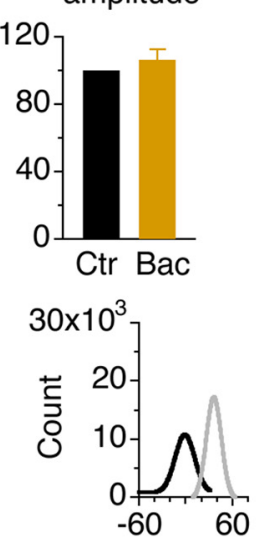

$30 \times 10^{3}$

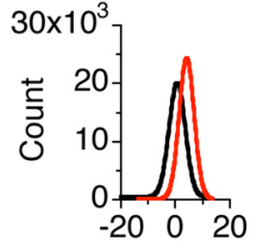

H

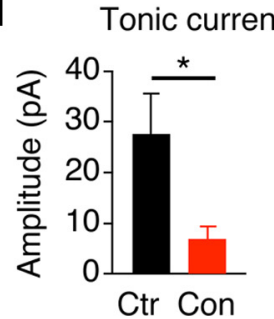

$2 \mu \mathrm{M}$ Concanamycin A
Phasic sIPSC

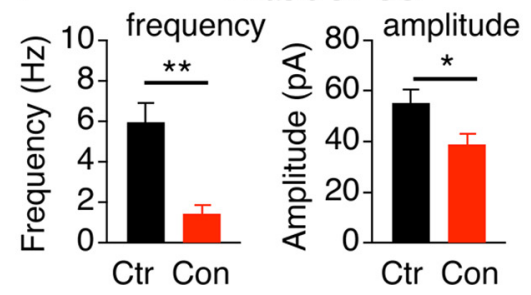

$\delta$-GABA ${ }_{\mathrm{A}}$ Rs mediate the tonic current

Next, we sought to identify the receptors mediating the tonic current in the NL. GABA $\mathrm{A}$ Rs are pentameric receptors, consisting of 5 of 19 possible subunits $(\alpha 1-6, \beta 1-3, \gamma 1-3, \delta, \varepsilon, \pi$, $\theta, \rho 1-3)$. Among these combinations, only a few ( $\alpha 4 \delta$-, $\alpha 6 \delta$-, $\alpha 5 \gamma$-, and $\varepsilon$-containing receptors) compose extrasynaptic $\mathrm{GABA}_{\mathrm{A}} \mathrm{Rs}$ with high GABA binding affinity and low desensitization properties (for review, see Farrant and Nusser, 2005). Tonic inhibition is markedly associated with the expression of either the $\delta$ subunit, which is exclusively present at extrasynaptic locations (Nusser et al., 1998), or the $\alpha 5$ subunit (Caraiscos et al., 2004; Ade et al., 2008). To address this, we took advantage of the distinct pharmacological properties displayed by $\mathrm{GABA}_{\mathrm{A}} \mathrm{Rs}$ related to their subunit constitution. Indeed, whereas $\delta$-GABA $\mathrm{A}_{\mathrm{A}}$ Rs are highly sensitive to the $\mathrm{GABA}_{\mathrm{A}} \mathrm{R}$ partial agonist THIP (Brown et al., 2002), they are insensitive to benzodiazepine-site ligands such as flurazepam (Cope et al., 2005). THIP, at several micromolar concentrations, is a specific agonist for native $\delta$-GABA $\mathrm{A}$ Rs (Cope et al., 2005; Maguire et al., 2005).

We found that THIP ( 1 or $3 \mu \mathrm{M} ; n=$ 6), but not flurazepam ( $5 \mu \mathrm{M} ; n=5)$, induced a significant increase of the tonic current (Fig. 2A-C, Table 1). THIP also decreased the amplitude of sIPSCs, without affecting their frequency or kinetics. Flurazepam prolonged the decay time constant of sIPSCs (control, $12.8 \pm 1.0$ ms; flurazepam, $14.4 \pm 1.3 \mathrm{~ms} ; n=5 ; p<$ 0.01 ), but did not affect their frequency or amplitude (Fig. $2 B, D$, Table 1 ). In contrast, L-655,708 (50 $\mu \mathrm{M})$, a selective antag-

\section{$\leftarrow$}

Figure 3. Experimental manipulations that reduce the release probability of GABA lead to a diminished tonic current. $\boldsymbol{A}$, Left, Representative recordings from a middle/high-CF neuron under normal (black) and zero extracellular $\mathrm{Ca}^{2+}$ (green) conditions. Right, Gaussian fits to all-point histograms of the baseline currents (control, black; $0 \mathrm{Ca}^{2+}$, green; SR95531, gray). $\boldsymbol{B}$, Summary data showing that low $\mathrm{Ca}^{2+}(n=5)$ significantly reduced the amplitude of the tonic current. $C$, Low $\mathrm{Ca}^{2+}$ reduced the frequency without changing the amplitude of sIPSCs. D, Baclofen $(100 \mu \mathrm{m})$, a GABA R Ragonist, suppressed the tonic current (control, black; baclofen, orange; SR95531, gray). $\boldsymbol{E}$, Summary data showing that baclofen $(n=5)$ significantly reduced the amplitude of the tonic current. $F$, Baclofen reduced the frequency without changing the amplitude of sIPSCS. G, Tonic current was not detectable in a middle/ high-CF neuron recorded from a brain slice incubated for $>1.5$ $h$ in ACSF containing concanamycin A $(2 \mu \mathrm{M})$, an inhibitor of vesicular $\mathrm{H}^{+}$-ATPase, whereas tonic current was evident in an NL neuron recorded from another slice incubated in the vehicle (0.5\% DMSO) (control, black; concanamycin A, red; SR95531, gray). $\boldsymbol{H}, \mathbf{I}$, Summary data showing that concanamycin $\mathrm{A}$ ( $n=$ 6) significantly reduced the amplitude of the tonic current, and the frequency and the amplitude of sIPSCs. 
onist for $\mathrm{GABA}_{\mathrm{A}} \mathrm{Rs}$ containing the $\alpha 5$ subunit (Caraiscos et al., 2004), did not change the tonic current (Table 1), indicating that $\mathrm{GABA}_{\mathrm{A}}$ Rs containing the $\delta$, but not the $\alpha 5$, subunit are responsible for the tonic current in the NL. The presence of the $\delta$ subunit is critical. The expression of this subunit in cerebellar granule cells (Nusser et al., 1998; Peng et al., 2002) is closely associated with a functional tonic inhibition (Hamann et al., 2002; Chadderton et al., 2004), whereas in granule cells of the dorsal cochlear nucleus, an anatomically and physiologically cerebellum-like structure, there is no tonic inhibition (Balakrishnan and Trussell, 2008), probably because of the lack of $\delta$ subunit (Campos et al., 2001). Interestingly, application of THIP $(3 \mu \mathrm{M})$ induced a small but significant outward current in low-CF cells (control, $2.7 \pm$ 2.0 pA; THIP, $12.6 \pm 2.4 \mathrm{pA} ; n=8 ; p<0.01$ ) (Fig. $2 E, F$ ), suggesting the presence of the $\delta$ subunit in the low-CF region, although the $\mathrm{GABA}_{\mathrm{A}}$ Rs containing this subunit may not be constitutively active in the slice preparation. Furthermore, the effects of THIP suggest that the tonic conductance can be modulated without enhancing the probability of temporal summation of sIPSCs. The fact that flurazepam prolonged sIPSCs but did not affect the tonic current further indicates that the tonic current does not result from temporal summation of sIPSCs.

Consistent with these findings, the presence of $\delta$ subunit in the NL was confirmed by Western blot analysis and immunostaining techniques (Fig. 2G-M). Antibodies against the rat $\delta$ subunit have been developed, and the GABRD gene, coding for the $\sim 450$ aa $\delta$ subunit, is conserved among human, chimpanzee, mouse, rat, dog, cow, and zebrafish. In the chicken, a predicted sequence, coding for a homologous 775 aa protein, has been described (National Center for Biotechnology Information accession number XP_001234041.1), with the protein being longer in the C-terminal domain by 347 aa than its mouse/rat counterparts. We first tested the specificity of the antibody in the chick by Western blot. The mouse cerebellum, where reactivity has been previously confirmed (Peng et al., 2002), was used as a positive control (54 kDa) (Fig. 2G, lane 1). In protein extracts from multiple chicken tissues (cerebellum, cerebrum, ventral part of the brainstem, and dorsal part of the brainstem containing the NL), a band was detected at the expected molecular weight of $\sim 85 \mathrm{kDa}$, as predicted from the primary amino acid sequence (Fig. $2 G$, lanes $2-5$ ). Interestingly, a $\sim 53 \mathrm{kDa}$ band was found in the chick brainstem (Fig. $2 G$, lanes 4 and 5). This could represent a splice variant of the subunit that corresponds to the first seven exons of the gene, the product of which corresponds to a 428 aa protein, highly similar to the human and mouse subunits. Because the antibody seemed to recognize the chick $\delta$ subunit, immunohistochemistry staining was performed. Mouse cerebellar tissues were used as positive controls (Fig. $2 H$ ). Strong immunoreactivity was observed in the cerebellum of the chick (Fig. $2 J$ ). Although the signal was relatively weak, the expression of the $\delta$ subunit was observed in NL neurons, without any obvious gradient distribution along the frequency axis (Fig. $2 L, M)(n=7$ animals). The staining appeared to be primarily located on the somatic membrane and diffusely distributed on the neuropils (Fig. $2 L, M$, insets).

\section{GABA spillover mediates the tonic current}

We next investigated the origins of GABA responsible for generating the tonic current. Ambient GABA could originate from synaptic spillover during vesicle release (for review, see Farrant and Nusser, 2005). To determine whether the tonic current is dependent on synaptic activity, we studied the effects of reducing GABA release on the tonic current. We first varied the extracellular $\mathrm{Ca}^{2+}$ concentration, hypothesizing that if the source of am-
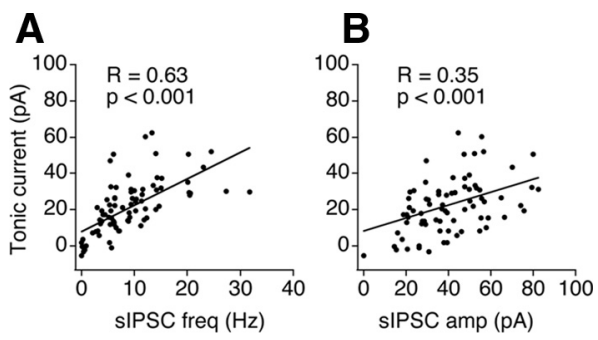

Figure 4. The tonic current is highly correlated with the phasic inhibition. Linear regression analyses show that the amplitude of the tonic current was positively correlated with the frequency $(\boldsymbol{A})$ and amplitude $(\boldsymbol{B})$ of sIPSCS $(n=81)$.

bient GABA was from synaptic release, reduction of the synaptic release probability by lowering extracellular $\mathrm{Ca}^{2+}$ concentration would reduce or abolish the tonic current. Indeed, $\mathrm{Ca}^{2+}$ removal significantly reduced the tonic current and significantly reduced the frequency of sIPSCs without affecting their amplitude (Fig. $3 A-C$, Table 1).

An alternative approach to modulate synaptic GABA release is by acting on G-protein-coupled $\mathrm{GABA}_{\mathrm{B}} \mathrm{Rs}$. We have previously shown that activation of presynaptic $G_{A B A}$ Rs reduces GABA release onto NL neurons (Tang et al., 2009). Indeed, application of baclofen $(100 \mu \mathrm{M})$, a selective $\mathrm{GABA}_{\mathrm{B}} \mathrm{R}$ agonist, reduced sIPSC frequency without altering their amplitude. Accordingly, the amplitude of the tonic current was reduced significantly $(n=5)$ (Fig. $3 D-F$, Table 1$)$. Because $G_{A B A}$ Rs also display a high affinity for GABA, we wondered whether ambient GABA could activate these receptors and thus regulate the tonic current, as shown in Cajal-Retzius cells of the mouse visual cortex (Kirmse and Kirischuk, 2006). In NL neurons, application of CGP52432 (20 $\mu \mathrm{M})$, a selective $\mathrm{GABA}_{\mathrm{B}} \mathrm{R}$ antagonist, affected neither sIPSCs nor the tonic current $(n=6 ; p>0.05)$ (Table 1$)$, indicating that presynaptic $\mathrm{GABA}_{\mathrm{B}}$ Rs are not activated by ambient GABA at rest in the NL.

We further confirmed our observations with concanamycin A, an inhibitor of vesicular $\mathrm{H}^{+}$-ATPase, which is known to abolish the $\mathrm{H}^{+}$gradient across the membrane of synaptic vesicles, preventing accumulation of neurotransmitters into vesicles (for review, see Dröse and Altendorf, 1997) and thus reducing synaptic transmission (Zhou et al., 2000). More interestingly, concanamycin A reduces the tonic current mediated by vesicular GABA release (Glykys and Mody, 2007a) but does not affect the tonic current mediated by nonvesicular GABA release (Rossi et al., 2003). This provides a useful pharmacological tool to determine the source of ambient GABA. We therefore took advantage of this tool by incubating the brain slices with either concanamycin A (2 $\mu \mathrm{M})$ or the vehicle DMSO $(0.5 \%)$ for $>1.5 \mathrm{~h}$ before physiological recordings. We found that tonic currents were hardly detectable in middle/high-CF NL neurons recorded from brain slices incubated in concanamycin A $(n=6)$, whereas tonic currents were evident in neurons recorded from control slices incubated in the vehicle $(n=5)$ (Fig. $3 G, H)$. Concanamycin A $(n=6)$ also significantly reduced the frequency and the amplitude of sIPSCs (Fig. 3I).

Our data indicate that GABA spillover from synaptic release sites at the GABAergic terminals innervating NL neurons constitutes the major source of the ambient GABA underlying the tonic current. This suggests a possible correlation between the tonic current and the phasic current. We therefore analyzed this relationship by plotting the tonic current amplitude against both the frequency and amplitude of sIPSCs. We detected a positive linear 

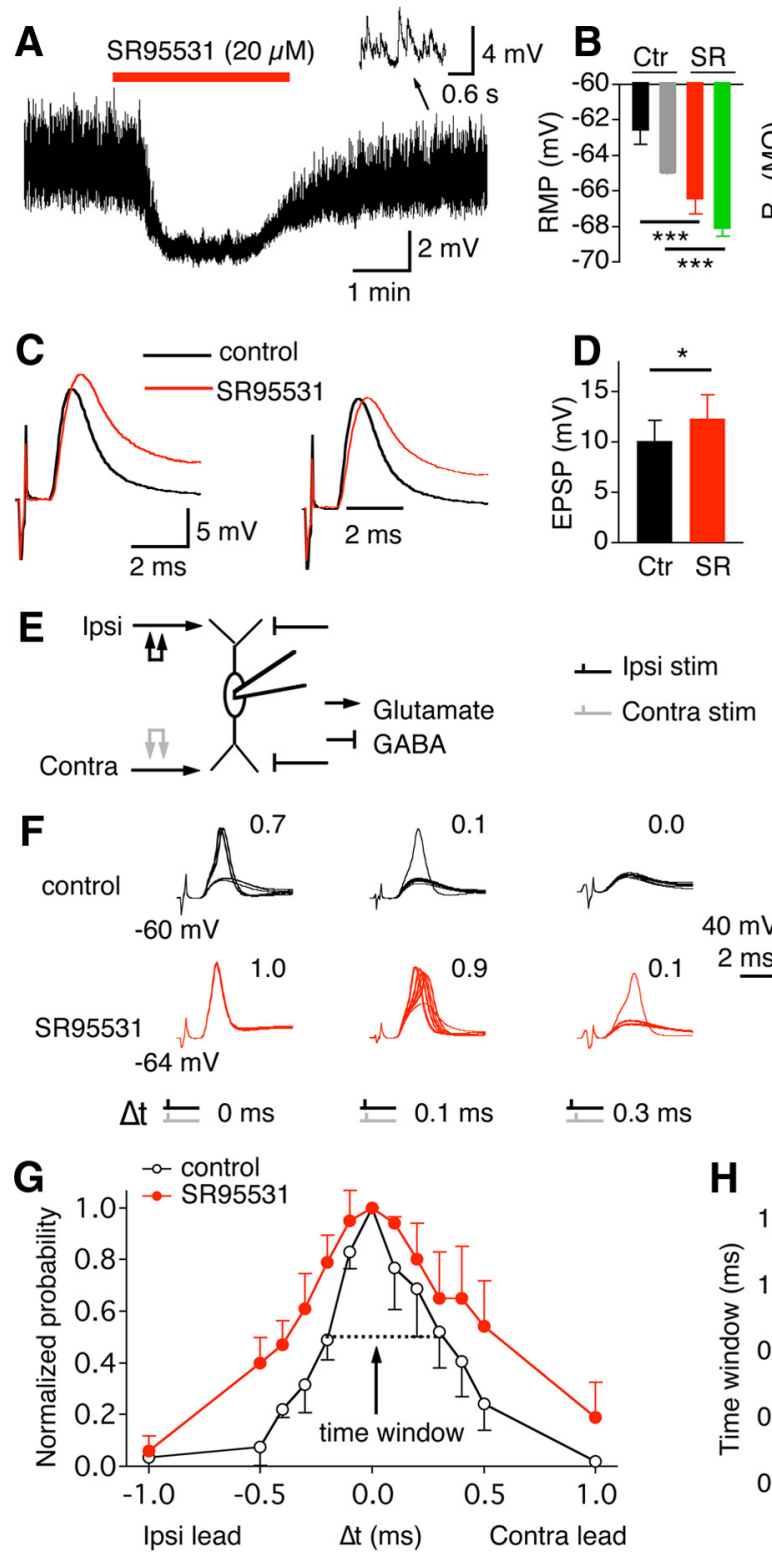

0.0
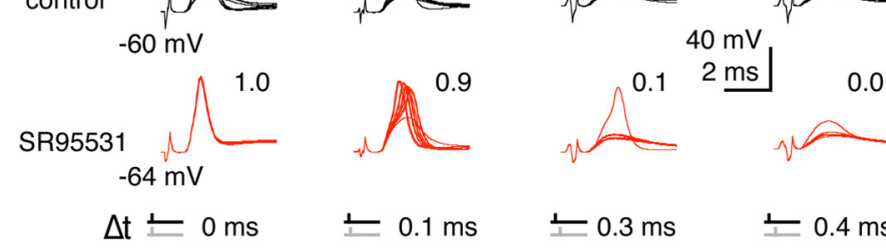

G

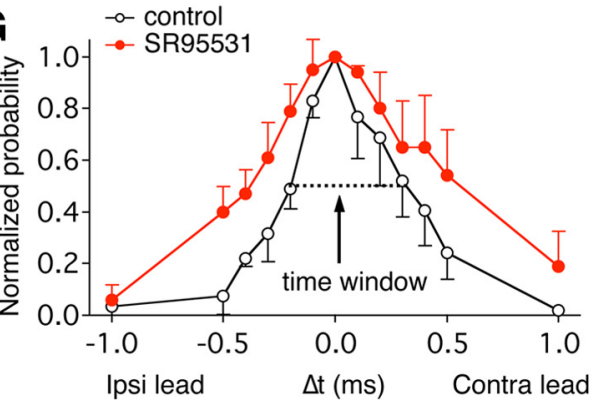

H

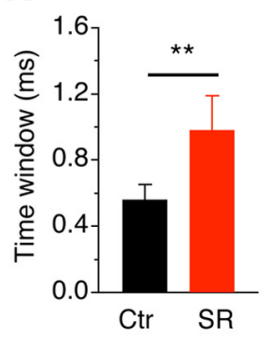

Figure 5. Blockade of endogenous $G_{A B A} R$ activity broadens both EPSPs and the time window for coincidence detection in middle/high-CF neurons. $A$, SR95531 (20 $\mu \mathrm{m})$ blocked sIPSPs and hyperpolarized the membrane. The inset shows a short period of the recording at an enlarged timescale. $\boldsymbol{B}$, SR95531 significantly hyperpolarized the membrane $(n=33)$ (black and red bars) and increased the input resistance $(n=11)$ (black and red bars). The same effects were observed when the initial membrane potential under the control conditions was adjusted to a fixed level $(-65 \mathrm{mV})$ with somatic current injections $(n=6)$ (gray and green bars). C, Left, EPSPs recorded with (red) and without (black) SR95531. Right, EPSPs normalized to their peak showing the time course. D, SR95531 significantly increased both the amplitude and the half-width (the time period at the half-amplitude) of EPSPs $(n=10)$. $\boldsymbol{E}$, Experimental paradigm. The two electrical stimuli (Ipsi and Contra) activate the dorsal and the ventral glutamatergic inputs, respectively. The time intervals between the two stimuli were varied to simulate the process of ITD coding. $F$, Voltage responses to bilateral stimulations with and without SR95531. Time intervals between the two stimulations are indicated on bottom of the panel. The numerical on the top right of each set of traces indicates the spike probability. $\mathbf{G}$, Normalized firing probabilities as a function of time intervals $(n=9)$. $\boldsymbol{H}$, SR95531 significantly increased the time window of coincidence detection $(n=9)$.

relationship between the tonic current and both sIPSC parameters $(n=81)$ (Fig. 4), indicating that the tonic current is highly correlated with the strength of the phasic current in the NL.

Tonic GABAergic inhibition sharpens coincidence detection Tonic inhibition contributes to "signal integration" in the brain by setting the threshold for action potential (AP) generation (Häusser and Clark, 1997; Brickley et al., 2001; Hamann et al., 2002) and
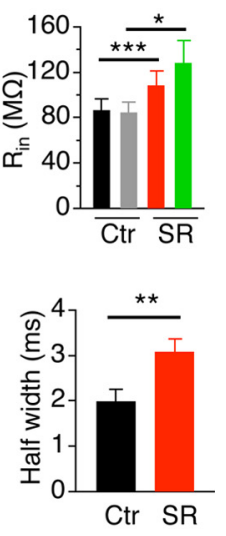

0.0

shunting the excitatory synaptic inputs (Brickley et al., 2001; Stell et al., 2003; Chadderton et al., 2004). To investigate the possible functional significance of the tonic current in NL neurons, we examined the effects of blocking the tonic current on their neuronal properties and on the process of coincidence detection. As expected, SR95531 produced a hyperpolarization of the resting membrane potential $(n=33)$ and a significant increase (by 25\%) in the input resistance $(n=11)$ (Fig. $5 A, B)$. The same effects were observed when the membrane potential under the control conditions was adjusted to a fixed level $(-65 \mathrm{mV})$ with somatic current injections $(n=6)$ (Fig. $5 B$, gray and green bars). SR95531 also significantly increased (by 22\%) the EPSP amplitude and half-width (the time period at the half amplitude) (Fig. 5C,D). The percentage change in the input resistance was comparable with that in the EPSP amplitude. When the initial membrane potential was fixed at $-65 \mathrm{mV}$, the increase in the input resistance was large (by $51 \%$ ). We did not measure the EPSPs of this group of neurons; therefore, it is unknown whether the change in the EPSP size was comparable with that in the input resistance.

Because the EPSP size and time course are negatively correlated with the acuity of coincidence detection (Kuba et al., 2002, 2003; Cook et al., 2003), we predicted that blocking the endogenous activation of $\mathrm{GABA}_{\mathrm{A}}$ Rs would compromise the precision of coincidence detection in middle/ high-CF neurons. To study the process of ITD coding in vitro, we recorded the voltage responses of NL neurons to electrical stimulations of the dorsal (ipsilateral) and ventral (contralateral) glutamatergic pathways at variable time intervals (Fig. $5 E-H$ ). The average firing probability was plotted against the stimulus time interval. The precision of coincidence detection was calculated as the time window, which was defined as the time period corresponding to the half-maximum firing probability (Fig. 5G). SR95531 (20 $\mu \mathrm{M})$ significantly decreased the precision of coincidence detection coding: the time window was broadened significantly, from $0.56 \pm 0.09$ to $0.98 \pm 0.21 \mathrm{~ms}(n=9 ; p<0.01)$ (Fig. $5 H)$. We therefore conclude that spontaneously released GABA-induced inhibition sharpens coincidence detection in NL neurons.

One limitation of these experiments is that the effects of the tonic inhibition cannot be separated from those of the phasic inhibition because of the lack of antagonistic mechanisms specific to $\delta$ - $\mathrm{GABA}_{\mathrm{A}} \mathrm{Rs}$ and possible activation of the GABAergic inputs by the ipsilateral stimulation that was desired to activate the ipsilateral glutamatergic inputs only. Whereas the contralateral stimulation appeared to activate the glutamatergic inputs only, the 
ipsilateral stimulation could activate both the glutamatergic and GABAergic inputs, especially when the stimulating electrode was placed in the area dorsal and lateral to the NL, as shown in our previous study [Tang et al. (2009), our Fig. 7]. The area dorsal and lateral to the NL seems to be where the glutamatergic projections from the ipsilateral NM to the NL and the GABAergic projections from the ipsilateral superior olivary nucleus (SON) to the NL mix and travel together. In the present study, the ipsilateral stimulating electrode was placed "in the NM" to avoid activating the GABAergic inputs originating from the SON. Even by doing so, we cannot completely exclude the possibility of activating some GABAergic inputs, because there are local GABAergic neurons sparsely distributed in and around the NM and NL (von Bartheld et al., 1989). To alleviate these limitations and to more specifically examine the role of tonic inhibition, we used the same experimental paradigm and studied the effects of an enhanced tonic inhibition on EPSPs and coincidence detection. We predicted that enhancing tonic inhibition would generate effects opposite to those of SR95531. Indeed, THIP (3 $\mu \mathrm{M})$ depolarized the membrane (control, $-68.9 \pm 1.1 \mathrm{mV}$; THIP, $-64.2 \pm 1.1 \mathrm{mV}$; $n=22 ; p<0.001)$, reduced the input resistance by $44 \%$ (control, $117.1 \pm 21.7 \mathrm{M} \Omega$; THIP, $65.7 \pm 13.5 \mathrm{M} \Omega ; n=9 ; p<0.01$ ), decreased EPSP amplitude by $21 \%$ (control, $6.1 \pm 0.6 \mathrm{mV}$; THIP, $4.8 \pm 0.4 \mathrm{mV} ; n=9$; $p<0.01)$, and shortened their half-width (control, $2.1 \pm 0.1 \mathrm{~ms}$; THIP, $1.6 \pm 0.1 \mathrm{~ms}$; $n=9 ; p<0.001)$. The reason for the differential percentage changes in the input resistance compared with the EPSP amplitude is unclear. The same effects were observed when the membrane potential under the control conditions was adjusted to a fixed level $(-65 \mathrm{mV})$ with somatic current injections $(n=6)$ (Fig. $6 B$, gray and green bars). Consistent with these effects, THIP narrowed the integration time window significantly from $0.55 \pm 0.11$ to $0.25 \pm 0.05 \mathrm{~ms}(n=8 ; p<0.01)$, improving coincidence detection (Fig. 6).

Finally, our experiments indicate that the effects of the tonic inhibition on EPSPs and consequently on coincidence detection rely mainly on a shunting mechanism. This conclusion is based on the observation that THIP $(3 \mu \mathrm{M})$ inhibited spontaneous spiking activity of NL neurons more effectively than did a simple positive-current injection into the recorded cells, which elicited approximately the same amount of membrane depolarization (Fig. 7A) $(n=3)$. Because the spontaneous spiking activity in brain slices was observed in only a small proportion of NL neurons, and because the spiking rate of the NL neurons that did fire spontaneously was very low, we increased the spontaneous firing by moderately inhibiting the $I_{\text {LTK }}$ with a specific blocker, dendrotoxin $(20-50 \mathrm{~nm})$. Dendrotoxin dramatically increased the
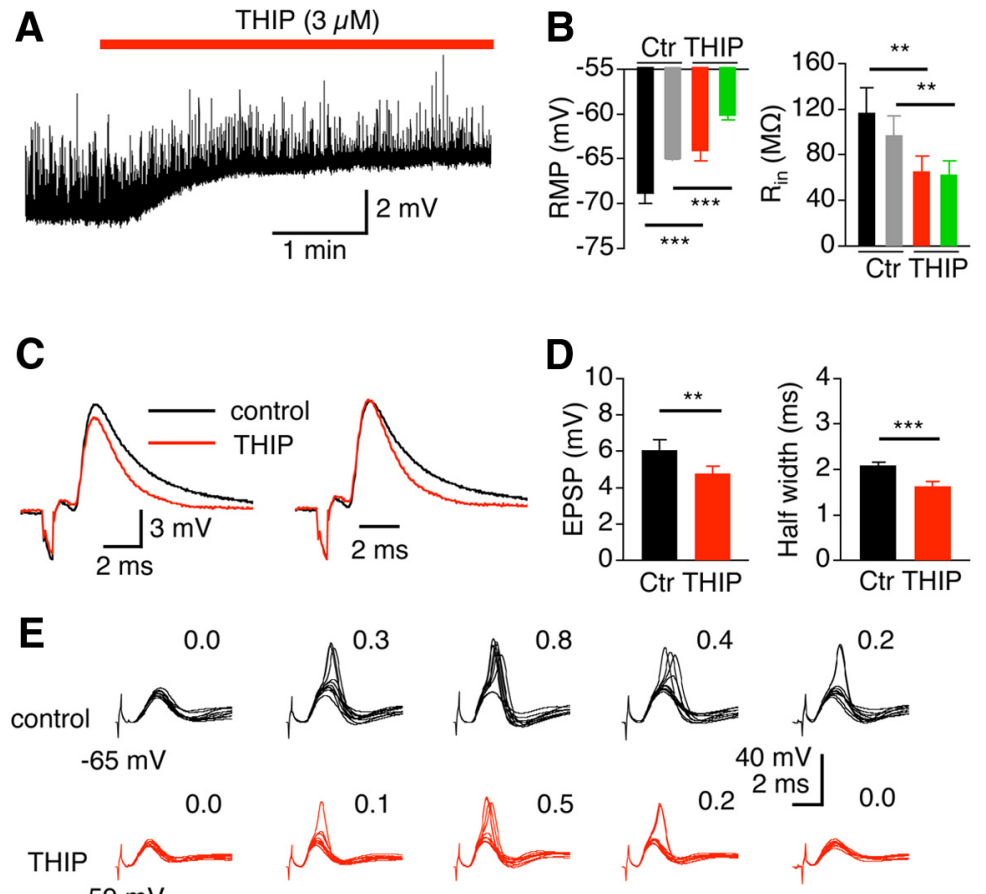

Enhancement of the tonic current sharpens both EPSPs and the time window for coincidence detection in middle/ al membrane potential under the control conditions was adjusted to a fixed level ( $-65 \mathrm{mV}$ ) with somatic current injections to bilateral stimulations with and without THIP. Time intervals between the two stimulations are indicated at the bottom of the panel. $\boldsymbol{F}$, Firing probabilities normalized to the maximum value $(n=8)$. $\boldsymbol{G}$, THIP significantly decreased the time window of coincidence detection $(n=8)$.

spontaneous firing, indicating that the $I_{\mathrm{LTK}}$ is highly active at the resting membrane potential, suppressing the excitability of NL neurons. Consistent with the results without dendrotoxin, THIP $(3 \mu \mathrm{M})$ significantly inhibited the spiking activity, whereas the same amount of membrane depolarization generated by positive current injections did not (Fig. $7 B-D ; n=6)$. Thus, activation of $\delta$-GABA $\mathrm{A}$ Rs proved to be a powerful mechanism to reduce the excitability of the NL neurons and to improve ITD coding.

\section{Discussion}

We report three major findings. First, we discovered a tonic inhibition mediated by $\delta$-GABA $\mathrm{A}_{\mathrm{A}}$ Rs in middle/high-CF neurons of the NL. This constitutes the first evidence of the presence of a tonic conductance activated by ambient GABA in the central auditory system. Second, this tonic inhibition sharpened EPSPs, reduced cellular excitability, and improved coincidence detection 


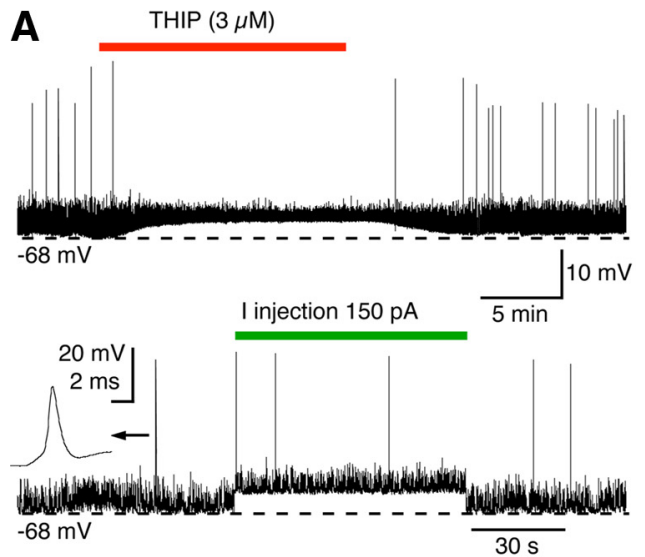

B THIP $(3 \mu \mathrm{M})$
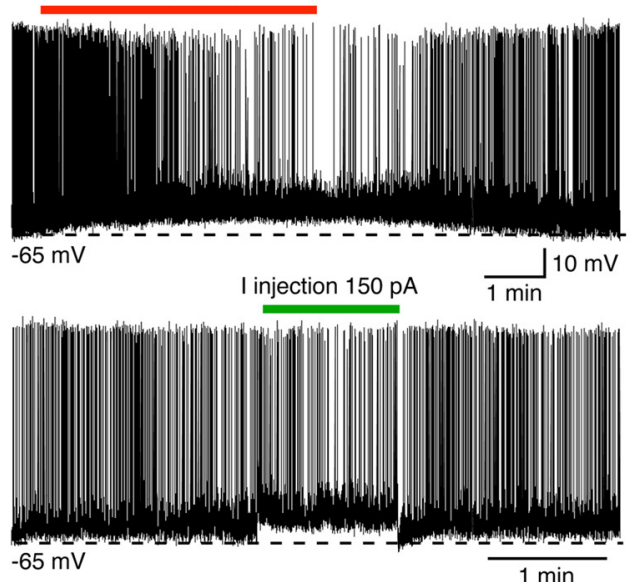

C
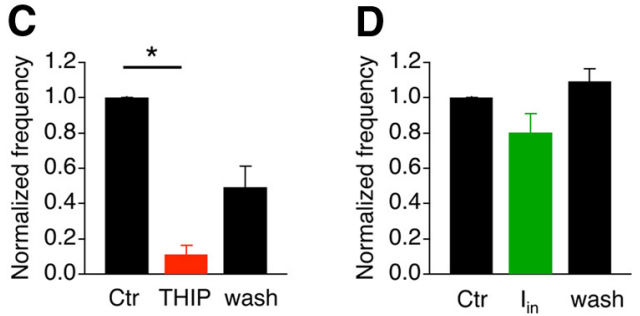

Figure 7. Shunting inhibition by activation of $\delta-G A B A_{A}$ Rs plays a major role in suppressing the excitability of middle/high-CF neurons. $\boldsymbol{A}$, THIP ( $3 \mu \mathrm{m})$ eliminated spontaneous APs, whereas a positive-current injection into the soma that elicited approximately the same amount of membrane depolarization did not. $\boldsymbol{B}$, The same phenomenon was observed in presence of dendrotoxin (20-50 nM), a blocker of $I_{\mathrm{LTK}}$, which caused a dramatic increase in the background spiking activity. $C, D$, THIP significantly reduced the firing rate of NL neurons in the presence of dendrotoxin, whereas current injections $\left(I_{\text {in }}\right)$ did not $(n=6)$.

in the NL, suggesting that the tonic conductance may facilitate the sound localization process. Finally, an unusually depolarizing shunting mechanism accounted for the inhibitory effects of the tonic GABA conductance.

\section{A $\delta$-GABA $A_{A} R$-mediated tonic current is present in NL neurons}

Three lines of evidence indicate that a tonic conductance mediated by $\delta$ - $\mathrm{GABA}_{\mathrm{A}}$ Rs is present in NL neurons. First, under normal physiological recording conditions, blocking $G_{A B A} R s$ revealed an outward tonic current. Despite the many factors that could have prevented the recording of tonic GABA activity in slice preparations (for review, see Glykys and Mody, 2007b), the detection of a tonic current in NL neurons strongly suggests the presence of extrasynaptic $\mathrm{GABA}_{\mathrm{A}}$ Rs with a high GABA-binding af- finity. Second, pharmacological evidence strongly indicates that the $\mathrm{GABA}_{\mathrm{A}}$ Rs mediating the tonic current in the NL contain the $\delta$ subunit. $\delta$-GABA $\mathrm{G}_{\mathrm{A}}$ Rs express several unique features. They are found exclusively at extrasynaptic sites (Nusser et al., 1998) and have a very high affinity for GABA (Saxena and MacDonald, 1996). The $\delta$ subunit also confers to the receptors slow desensitization, high sensitivity to THIP (Brown et al., 2002), and low sensitivity to enhancers of synaptic $\mathrm{GABA}_{\mathrm{A}}$ Rs such as benzodiazepine derivatives (Nusser and Mody, 2002; Cope et al., 2005). The tonic current in NL neurons was highly sensitive to THIP but insensitive to the benzodiazepine agonist flurazepam, suggesting that $\delta$-GABA $\mathrm{A}$ s mediated the current. Third, anatomical approaches demonstrated the expression of the $\delta$ subunit in NL neurons.

Interestingly, physiological results showed that expression of this tonic current is CF dependent in the NL. One plausible explanation would be that low-CF neurons have a lower level expression of the $\delta$ subunit than middle/high-CF neurons, as the differential expression of the $\delta$ subunit has been associated with differential amplitudes of the tonic current in hippocampal neurons (Wei et al., 2003). However, we did not observe obvious differences in the expression of the $\delta$ subunit between low-CF and middle/high-CF regions of the NL. An alternative explanation for the CF-dependent tonic current is a differential release probability between these CF regions. The low frequency of sIPSCs in low-CF NL neurons suggests a low release probability of GABA. Consequently, the neurons display a smaller tonic current because of a low propensity for spillover (Semyanov et al., 2003). Functionally, the presence of a small tonic current in low-CF neurons suggests that phasic inhibition may play a major role in ITD coding in these neurons, as suggested in mammalian MSO neurons where a phasic glycinergic inhibition may shape their ITD coding (for review, see Grothe, 2003).

\section{Synaptically released GABA accounts for the tonic current in NL neurons}

The concentration of ambient GABA ranges from tens of nanomolar to a few micromolar, and both vesicular and nonvesicular releases contribute to the ambient GABA level (for review, see Cavelier et al., 2005). The major source for ambient GABA in the $\mathrm{NL}$ arises from synaptic release, because the activation levels of phasic and tonic inhibitions are highly correlated. Low extracellular $\mathrm{Ca}^{2+}$ conditions reduce the release probability, and baclofen, by activating presynaptic $\mathrm{GABA}_{\mathrm{B}} \mathrm{Rs}$, suppresses GABA release onto the NL (Tang et al., 2009). Both manipulations led to a diminished tonic current. These results also suggest that the contribution of nonsynaptic sources, such as release of GABA via reversed transporter activity (for review, see Richerson and $\mathrm{Wu}$, 2003) or astrocyte release (Kozlov et al., 2006; Lee et al., 2010), is minimal in the NL. This conclusion is further supported by the experiments in which tonic currents were not evident in middle/ high-CF NL neurons recorded from the brain slices pretreated with concanamycin A. Therefore, tonic inhibition in the NL depends on the GABA release that causes phasic inhibition, similar to what has been reported in thalamic relay neurons of the dorsal lateral geniculate nucleus (Bright et al., 2007) and neurons of the mouse hippocampus (Glykys and Mody, 2007a). Neurons in the NL receive GABAergic inputs from two origins: GABAergic neurons located in the ipsilateral SON (Lachica et al., 1994; Yang et al., 1999; Burger et al., 2005) and local interneurons around the NL (von Bartheld et al., 1989), with the former being the primary source. Because of technical limitations, these two GABA sources were not studied separately. 


\section{Functional significance: implication in ITD coding}

We propose that the depolarizing tonic $\mathrm{GABA}_{\mathrm{A}}$ conductance contributes to temporal coding in the NL through multiple pathways. First, and the most important, a tonic $\mathrm{GABA}_{\mathrm{A}}$ conductance produces a shunting inhibition at rest. This shunting inhibition would decrease the amplitude of the membrane voltage change to a given current input and thus would elevate spiking threshold. Indeed, our data provide evidence that activation of the tonic current reduces EPSP amplitude and decreases spontaneous firing rate. A consequence of this would be a scarcer spiking activity of NL neurons in response to monaural inputs, ensuring proper coincidence detection of the converging binaural inputs. Another outcome of the shunting inhibition would be a larger voltage decrement over the distance from the input sites, which would further reduce the membrane time constant and sharpen the time window for coincidence detection. Our data support this interpretation and are in accordance with previous studies in which exogenous GABA was applied onto NL neurons (Brückner and Hyson, 1998; Funabiki et al., 1998). Second, because of its depolarizing nature, the tonic $\mathrm{GABA}_{\mathrm{A}}$ conductance in the NL would depolarize the cellular membrane and activate $I_{\text {LTK. }}$. In turn, activation of $I_{\text {LTK }}$ controls EPSP width, prevents the membrane potential from reaching the spike threshold, and preserves binaural synaptic timing (Mathews et al., 2010). Our results indicate that the tonic $\mathrm{GABA}_{\mathrm{A}}$ conductance and the $I_{\mathrm{LTK}}$ work synergistically toward producing a leaky and thus a fast membrane; indeed, activation of the tonic conductance proved to be more efficient in regulating the NL excitability than a mechanism involving only a depolarization of the membrane. Again, the outcome will decrease the time window for coding convergent excitatory inputs. Third, the partial inactivation of $\mathrm{Na}^{+}$channels as a consequence of membrane depolarization would further elevate the spiking threshold (Kuba et al., 2006; Howard and Rubel, 2010). Therefore, the tonic inhibition may limit ongoing firing of NL neurons in vivo and shape spontaneous firing patterns in such a way that NL neurons are biased toward responding to converging bilateral excitatory inputs in a rapid and sensitive manner.

This tonic GABAergic inhibition might be functionally similar to the sustained inhibition formed by temporal summation of the synaptic GABA currents in the NL (Yang et al., 1999; Monsivais and Rubel, 2001) or by asynchronous GABA release in the nucleus magnocellularis ( $\mathrm{Lu}$ and Trussell, 2000). However, these two forms of GABA inhibition exert their actions at different physiological stages. Phasic inhibition caused by AP-induced GABA release forms a long-lasting inhibitory tone during highfrequency activity. This is a consequence of temporal summation of synaptic currents (Yang et al., 1999), perhaps associated with the dominant role of N-type calcium channels in triggering GABA release at NL (Lu, 2009), which would facilitate asynchronous release of GABA and thus temporal summation of sIPSCs (Hefft and Jonas, 2005). In contrast, the tonic $\mathrm{GABA}_{\mathrm{A}}$ conductance provides a persistent shunt and leads to subsequent activation of $I_{\text {LTK }}$. We propose that this tonic conductance, already present at rest, sets the baseline for a sharp time window in encoding the bilateral converging excitatory inputs for sound localization. At higher frequencies of synaptic inputs, phasic and tonic inhibitions act together to further enhance the precision of temporal coding.

Because tonic inhibition has functional consequences, its magnitude is presumably subject to modulation. Although $\mathrm{GABA}_{\mathrm{B}} \mathrm{Rs}$ have a high GABA-binding affinity, they are not activated by the basal level of endogenous GABA in the NL, a finding similar to what has been reported in mouse neostriatal neurons (Kirmse et al., 2008). Therefore, tonic inhibition in the NL is executed mainly via $\mathrm{GABA}_{\mathrm{A}}$ activity. However, because of the correlation between phasic inhibition and tonic inhibition, modulation of phasic inhibition by G-protein-coupled receptors (GPCRs) will inevitably regulate the concentration of ambient GABA and thus the level of tonic inhibition. This is in contrast to cases in which the tonic current is independent of AP-evoked release of GABA and hence the tonic activity is not affected by GPCRs (Rossi et al., 2003). In the NL, the evoked IPSCs are dynamically modulated by both $\mathrm{GABA}_{\mathrm{B}}$ autoreceptors and metabotropic glutamate heteroreceptors (Tang et al., 2009). The suppression of evoked GABA release is expected to reduce GABA spillover and thus modulate the dynamics of the tonic current, as evidenced by the effects of baclofen on its amplitude. Therefore, we propose that a persistent $\mathrm{GABA}_{\mathrm{A}} \mathrm{R}$ current maintains an inhibitory tone, generating a shunting inhibition at rest in NL neurons and complementing the inhibition mediated by synaptic $\mathrm{GABA}_{\mathrm{A}} \mathrm{Rs}$, whereas $\mathrm{GABA}_{\mathrm{B}} \mathrm{Rs}$ control the dynamic strength of phasic inhibition.

\section{References}

Ade KK, Janssen MJ, Ortinski PI, Vicini S (2008) Differential tonic GABA conductances in striatal medium spiny neurons. J Neurosci 28:1185-1197.

Agmon-Snir H, Carr CE, Rinzel J (1998) The role of dendrites in auditory coincidence detection. Nature 393:268-272.

Balakrishnan V, Trussell LO (2008) Synaptic inputs to granule cells of the dorsal cochlear nucleus. J Neurophysiol 99:208-219.

Belelli D, Harrison NL, Maguire J, Macdonald RL, Walker MC, Cope DW (2009) Extrasynaptic $\mathrm{GABA}_{\mathrm{A}}$ receptors: form, pharmacology, and function. J Neurosci 29:12757-12763.

Brickley SG, Revilla V, Cull-Candy SG, Wisden W, Farrant M (2001) Adaptive regulation of neuronal excitability by a voltage-independent potassium conductance. Nature 409:88-92.

Bright DP, Aller MI, Brickley SG (2007) Synaptic release generates a tonic $\mathrm{GABA}_{\mathrm{A}}$ receptor-mediated conductance that modulates burst precision in thalamic relay neurons. J Neurosci 27:2560-2569.

Brown N, Kerby J, Bonnert TP, Whiting PJ, Wafford KA (2002) Pharmacological characterization of a novel cell line expressing human $\alpha_{4} \beta_{3} \delta$ $\mathrm{GABA}_{\mathrm{A}}$ receptors. Br J Pharmacol 136:965-974.

Brückner S, Hyson RL (1998) Effect of GABA on the processing of interaural time differences in nucleus laminaris neurons in the chick. Eur J Neurosci 10:3438-3450.

Burger RM, Rubel EW (2007) Encoding of interaural timing for binaural hearing. In: The senses: a comprehensive reference, $\mathrm{Vol} 3$, Audition (Dallos P, Oertel D, eds), pp 613-630. San Diego: Academic.

Burger RM, Cramer KS, Pfeiffer JD, Rubel EW (2005) Avian superior olivary nucleus provides divergent inhibitory input to parallel auditory pathways. J Comp Neurol 481:6-18.

Campos ML, de Cabo C, Wisden W, Juiz JM, Merlo D (2001) Expression of $\mathrm{GABA}_{\mathrm{A}}$ receptor subunits in rat brainstem auditory pathways: cochlear nuclei, superior olivary complex and nucleus of the lateral lemniscus. Neuroscience 102:625-638.

Caraiscos VB, Elliott EM, You-Ten KE, Cheng VY, Belelli D, Newell JG, Jackson MF, Lambert JJ, Rosahl TW, Wafford KA, MacDonald JF, Orser BA (2004) Tonic inhibition in mouse hippocampal CAl pyramidal neurons is mediated by $\alpha 5$ subunit-containing $\gamma$-aminobutyric acid type $\mathrm{A}$ receptors. Proc Natl Acad Sci U S A 101:3662-3667.

Carr CE, Fujita I, Konishi M (1989) Distribution of GABAergic neurons and terminals in auditory system of the barn owl. J Comp Neurol 286:190-207.

Cavelier P, Hamann M, Rossi D, Mobbs P, Attwell D (2005) Tonic excitation and inhibition of neurons: ambient transmitter sources and computational consequences. Prog Biophys Mol Biol 87:3-16.

Chadderton P, Margrie TW, Häusser M (2004) Integration of quanta in cerebellar granule cells during sensory processing. Nature 428:856-860.

Chance FS, Abbott LF, Reyes AD (2002) Gain modulation from background synaptic input. Neuron 35:773-782.

Code RA, Burd GD, Rubel EW (1989) Development of GABA immunoreactivity in brainstem auditory nuclei of the chick: ontogeny of gradients in terminal staining. J Comp Neurol 284:504-518.

Cook DL, Schwindt PC, Grande LA, Spain WJ (2003) Synaptic depression in the localization of sound. Nature 421:66-70. 
Cope DW, Hughes SW, Crunelli V (2005) $\mathrm{GABA}_{\mathrm{A}}$ receptor-mediated tonic inhibition in thalamic neurons. J Neurosci 25:11553-11563.

Debarbieux F, Brunton J, Charpak S (1998) Effect of bicuculline on thalamic activity: a direct blockade of $I_{\mathrm{AHP}}$ in reticularis neurons. J Neurophysiol 79:2911-2918.

Dröse S, Altendorf K (1997) Bafilomycins and concanamycins as inhibitors of V-ATPases and P-ATPases. J Exp Biol 200:1-8.

Farrant M, Nusser Z (2005) Variations on an inhibitory theme: phasic and tonic activation of $\mathrm{GABA}_{\mathrm{A}}$ receptors. Nat Rev Neurosci 6:215-229.

Funabiki K, Koyano K, Ohmori H (1998) The role of GABAergic inputs for coincidence detection in the neurones of nucleus laminaris of the chick. J Physiol 508:851-869.

Glykys J, Mody I (2007a) The main source of ambient GABA responsible for tonic inhibition in the mouse hippocampus. J Physiol 582:1163-1178.

Glykys J, Mody I (2007b) Activation of GABA $\mathrm{A}_{\mathrm{A}}$ receptors: views from outside the synaptic cleft. Neuron 56:763-770.

Glykys J, Peng Z, Chandra D, Homanics GE, Houser CR, Mody I (2007) A new naturally occurring $\mathrm{GABA}_{\mathrm{A}}$ receptor subunit partnership with high sensitivity to ethanol. Nat Neurosci 10:40-48.

Gray L, Rubel EW (1985) Development of absolute thresholds in chickens. J Acoust Soc Am 77:1162-1172.

Grothe B (2003) New roles for synaptic inhibition in sound localization. Nat Rev Neurosci 4:540-550.

Hamann M, Rossi DJ, Attwell D (2002) Tonic and spillover inhibition of granule cells control information flow through cerebellar cortex. Neuron 33:625-633.

Häusser M, Clark BA（1997) Tonic synaptic inhibition modulates neuronal output pattern and spatiotemporal synaptic integration. Neuron 19: $665-678$.

Hefft S, Jonas P (2005) Asynchronous GABA release generates long-lasting inhibition at a hippocampal interneuron-principal neuron synapse. Nat Neurosci 8:1319-1328.

Howard MA, Rubel EW (2010) Dynamic spike thresholds during synaptic integration preserve and enhance temporal response properties in the avian cochlear nucleus. J Neurosci 30:12063-12074.

Jackson H, Rubel EW (1978) Ontogeny of behavioral responsiveness to sound in the chick embryo as indicated by electrical recordings of motility. J Comp Physiol Psychol 92:682-696.

Kandler K, Clause A, Noh J (2009) Tonotopic reorganization of developing auditory brainstem circuits. Nat Neurosci 12:711-717.

Kaneda M, Farrant M, Cull-Candy SG (1995) Whole-cell and singlechannel currents activated by GABA and glycine in granule cells of the rat cerebellum. J Physiol 485:419-435.

Kirmse K, Kirischuk S (2006) Ambient GABA constrains the strength of GABAergic synapses at Cajal-Retzius cells in the developing visual cortex. J Neurosci 26:4216-4227.

Kirmse K, Dvorzhak A, Kirischuk S, Grantyn R (2008) GABA transporter 1 tunes GABAergic synaptic transmission at output neurons of the mouse neostriatum. J Physiol 586:5665-5678.

Kozlov AS, Angulo MC, Audinat E, Charpak S (2006) Target cell-specific modulation of neuronal activity by astrocytes. Proc Natl Acad Sci U S A 103:10058-10063.

Kuba H, Koyano K, Ohmori H (2002) Synaptic depression improves coincidence detection in the nucleus laminaris in brainstem slices of the chick embryo. Eur J Neurosci 15:984-990.

Kuba H, Yamada R, Ohmori H (2003) Evaluation of the limiting acuity of coincidence detection in nucleus laminaris of the chicken. J Physiol 552:611-620.

Kuba H, Ishii TM, Ohmori H (2006) Axonal site of spike initiation enhances auditory coincidence detection. Nature 444:1069-1072.

Lachica EA, Rübsamen R, Rubel EW (1994) GABAergic terminals in nucleus magnocellularis and laminaris originate from the superior olivary nucleus. J Comp Neurol 348:403-418.

Lee S, Yoon BE, Berglund K, Oh SJ, Park H, Shin HS, Augustine GJ, Lee CJ (2010) Channel-mediated tonic GABA release from glia. Science 330:790-796.

Lu T, Trussell LO (2000) Inhibitory transmission mediated by asynchronous transmitter release. Neuron 26:683-694.

Lu Y (2009) Regulation of glutamatergic and GABAergic neurotransmission in the chick nucleus laminaris: role of N-type calcium channels. Neuroscience 164:1009-1019.
Maguire J, Mody I (2008) $\mathrm{GABA}_{\mathrm{A}} \mathrm{R}$ plasticity during pregnancy: relevance to postpartum depression. Neuron 59:207-213.

Maguire JL, Stell BM, Rafizadeh M, Mody I (2005) Ovarian cycle-linked changes in $\mathrm{GABA}_{\mathrm{A}}$ receptors mediating tonic inhibition alter seizure susceptibility and anxiety. Nat Neurosci 8:797-804.

Mann EO, Mody I (2010) Control of hippocampal gamma oscillation frequency by tonic inhibition and excitation of interneurons. Nat Neurosci 13:205-212.

Mathews PJ, Jercog PE, Rinzel J, Scott LL, Golding NL (2010) Control of submillisecond synaptic timing in binaural coincidence detectors by Kvl channels. Nat Neurosci 13:601-609.

Mitchell SJ, Silver RA (2003) Shunting inhibition modulates neuronal gain during synaptic excitation. Neuron 38:433-445.

Monsivais P, Rubel EW (2001) Accommodation enhances depolarizing inhibition in central neurons. J Neurosci 21:7823-7830.

Nusser Z, Mody I (2002) Selective modulation of tonic and phasic inhibitions in dentate gyrus granule cells. J Neurophysiol 87:2624-2628.

Nusser Z, Sieghart W, Somogyi P (1998) Segregation of different GABA receptors to synaptic and extrasynaptic membranes of cerebellar granule cells. J Neurosci 18:1693-1703.

Parks TN, Rubel EW (1975) Organization and development of brain stem auditory neclei of the chicken: organization of projections from n. magnocellularis to n. laminaris. J Comp Neurol 164:435-448.

Peng Z, Hauer B, Mihalek RM, Homanics GE, Sieghart W, Olsen RW, Houser CR (2002) $\mathrm{GABA}_{\mathrm{A}}$ receptor changes in $\delta$ subunit-deficient mice: altered expression of $\alpha 4$ and $\gamma 2$ subunits in the forebrain. J Comp Neurol 446:179-197.

Reyes AD, Rubel EW, Spain WJ (1994) Membrane properties underlying the firing of neurons in the avian cochlear nucleus. J Neurosci 14:5352-5364.

Reyes AD, Rubel EW, Spain WJ (1996) In vitro analysis of optimal stimuli for phase-locking and time-delayed modulation of firing in avian nucleus laminaris neurons. J Neurosci 16:993-1007.

Richerson GB, Wu Y (2003) Dynamic equilibrium of neurotransmitter transporters: not just for reuptake anymore. J Neurophysiol 90: 1363-1374.

Rossi DJ, Hamann M, Attwell D (2003) Multiple modes of GABAergic inhibition of rat cerebellar granule cells. J Physiol 548:97-110.

Rubel EW, Parks TN (1975) Organization and development of brain stem auditory nuclei of the chicken: tonotopic organization of n. magnocellularis and n. laminaris. J Comp Neurol 164:411-433.

Ruiz A, Campanac E, Scott RS, Rusakov DA, Kullmann DM (2010) Presynaptic $\mathrm{GABA}_{\mathrm{A}}$ receptors enhance transmission and LTP induction at hippocampal mossy fiber synapses. Nat Neurosci 13:431-438.

Salin PA, Prince DA (1996) Spontaneous GABA receptor-mediated inhibitory currents in adult rat somatosensory cortex. J Neurophysiol 75:1573-1588.

Saxena NC, MacDonald RL (1996) Properties of putative cerebellar $\gamma$-aminobutyric acid A receptor isoforms. Mol Pharmacol 49:567-579.

Seidl AH, Rubel EW, Harris DM (2010) Mechanisms for adjusting interaural time differences to achieve binaural coincidence detection. J Neurosci 30:70-80.

Semyanov A, Walker MC, Kullmann DM (2003) GABA uptake regulates cortical excitability via cell type-specific tonic inhibition. Nat Neurosci 6:484-490.

Shen H, Sabaliauskas N, Sherpa A, Fenton AA, Stelzer A, Aoki C, Smith SS (2010) A critical role for $\alpha 4 \beta \delta \mathrm{GABA}_{\mathrm{A}}$ receptors in shaping learning deficits at puberty in mice. Science 327:1515-1518.

Stell BM, Brickley SG, Tang CY, Farrant M, Mody I (2003) Neuroactive steroids reduce neuronal excitability by selectively enhancing tonic inhibition mediated by $\delta$ subunit-containing $\mathrm{GABA}_{\mathrm{A}}$ receptors. Proc Natl Acad Sci U S A 100:14439-14444.

Tang ZQ, Gao H, Lu Y (2009) Control of a depolarizing GABAergic input in an auditory coincidence detection circuit. J Neurophysiol 102:1672-1683.

von Bartheld CS, Code RA, Rubel EW (1989) GABAergic neurons in brainstem auditory nuclei of the chick: distribution, morphology, and connectivity. J Comp Neurol 287:470-483.

Wei W, Zhang N, Peng Z, Houser CR, Mody I (2003) Perisynaptic localization of $\delta$ subunit-containing $\mathrm{GABA}_{\mathrm{A}}$ receptors and their activation by GABA spillover in the mouse dentate gyrus. J Neurosci 23:10650-10661.

Yang L, Monsivais P, Rubel EW (1999) The superior olivary nucleus and its influence on nucleus laminaris: a source of inhibitory feedback for coincidence detection in the avian auditory brainstem. J Neurosci 19: 2313-2325.

Zhou Q, Petersen CC, Nicoll RA (2000) Effects of reduced vesicular filling on synaptic transmission in rat hippocampal neurons. J Physiol 525:195-206. 